\title{
INTERVIEW WITH CHRIS DEDE
}

For a special issue of the Journal of Asynchronous Learning Networks (JALN), Conducted March 9, 2007 by Anthony G. Picciano

\section{BIOGRAPHY}

Chris Dede is the Timothy E. Wirth Professor of Learning Technologies at Harvard's Graduate School of Education. His fields of scholarship include emerging technologies, policy, and leadership. His funded research includes a grant from the National Science Foundation to aid middle school students learning science via shared virtual environments and a Star Schools grant from the U.S. Department of Education to help high school students with math and literacy skills using wireless mobile devices to create augmented reality simulations. Chris has served as a member of the National Academy of Sciences Committee on Foundations of Educational and Psychological Assessment, a member of the U.S. Department of Education's Expert Panel on Technology, and International Steering Committee member for the Second International Technology in Education Study. He serves on Advisory Boards and Commissions for PBS TeacherLine, the Partnership for 21st Century Skills, the Pittsburgh Science of Learning Center, and several federal research grants. In addition, Chris is a member of the Board of Directors of the Boston Tech Academy, an experimental small high school in the Boston Public School system, funded by the Gates Foundation. His co-edited book, Scaling Up Success: Lessons Learned from Technology-based Educational Improvement, was published by Jossey-Bass in 2005. A second volume he edited, Online Professional Development for Teachers: Emerging Models and Methods, was published by the Harvard Education Press in 2006. Links to his courses, projects, and writings are available on his webpage: http://www.gse.harvard.edu/ dedech/.

\section{INTERVIEW}

Interviewer: Over the years, reference has been made to the revolution that is going on with technology and K-12 education. Has this revolution occurred and we don't realize it, or has it been more of an evolution and is slowly changing the way we teach and learn?

[CD] While worthy, the models of technology-based and distance learning implemented by schools thus far are typically oriented to enabling and enhancing conventional forms of instruction. Teachers communicate with students across distance in ways essentially similar to how they interact with students face-to-face; generally, their pedagogy does not shift to take into account the full strengths of media for informing, sharing, and expressing. As an example, two-way interactive television (I-TV) is used primarily to enable students in a geographically remote setting to interact as if they were co-located with the teacher. When teacher professional development is offered across distance, the instructional model is often similar: face-to-face learning repackaged for remote delivery, via video or Internet-based presentations, readings, and discussions.

Research documents that this form of instruction is effective, but the exclusive use of such models of pedagogy can lead to a deficit perspective on learning technologies: A remote participant is perceived to have "almost" as good a cognitive, affective, and social experience as those immediately present with the teacher. Distance media are seen as replicating, as much as possible, a face-to-face learning experience without adding value to instruction beyond that replication. 
Advanced developments in technology-based and distance education are now generating novel instructional strategies based on the capabilities of new interactive media and the learning styles and strengths of Internet-generation students. The value of conventional technology-based and distance learning models is well understood and documented; coming next are potentially transformative strategies for teaching and learning that sophisticated information and communication technologies now enable for students, teachers, and communities. Finally, educators are beginning to recognize the added value of information and communication technologies in aiding learning, whether used as a complement to faceto-face instruction (hybrid, blended, or distributed approaches) or as a means of instruction without colocated personal presence (distance education).

Some emerging technologies are incremental improvements on existing applications, perhaps through changes in delivery system. Weblogs ("blogs") and podcasts fall into this category; blogs are similar to an electronically indexed daily diary, and podcasts are much like a recorded radio show. While such media can provide gains over their prior counterparts, usually the hype surrounding them exceeds their actual capacity for adding educational value. In the case of blogs and podcasts, for example, the real value is not the media themselves, but the opportunities for self-publishing and knowledge sharing they enable. The field of education is hopefully outgrowing the "This new medium is magic!” syndrome.

Other emerging technologies offer new, substantial capabilities for learning. For example, wikis provide the opportunity for multiple participants to co-create documents across distance. We know this capability is very useful in face-to-face collaborative learning, exemplified by such activities as design team members sketching simultaneously on a large, shared whiteboard, annotating each other's ideas. As the curriculum standards championed by The Partnership for 21st Century Skills illustrate, the capability to provide virtual collaborative workspaces shared across distance is valuable not only for learning, but also for preparing students to work in a global, knowledge-based economy. Schools may find wikis particularly valuable in distance learning situations in which too small a number of local students are enrolled to enable powerful forms of face-to-face peer collaboration.

Another type of emerging technology likely to add significant value for learning in schools is "sociosemantic networking." With my doctoral student, Adam Seldow, I have a grant from Harvard's Provost to explore this interactive medium. Adam and I believe that the many websites created early in the 21st century fueled efforts to categorize and organize the Web in order to empower users seeking to find "needles in haystacks." Google, Yahoo!, AOL, and others developed complex page ranking systems and algorithms to link information seekers to pertinent resources. Finding what one wanted on the Web became easier, but organizing and saving these resources was increasingly harder. Online communities clamored for intuitive ways to store and share their "gold mine" resources with friends and colleaguesenter the social bookmarking revolution. 2003-2004 marked the release of del.icio.us, furl, simpy, and Flickr, some of the more popular online social bookmarking communities. Instead of saving websites to their browsers and photos to their computers, individuals began saving bookmarks and photos online, sharing them with others, and-most importantly-labeling the items with words they could remember. This bottom-up, participant-driven method of identifying bookmarks and photos with personalized keywords adopted the industry moniker "social tagging" and the process of creating online, communitybased meaning for content was born.

Due to their ability to quickly react and adapt to changes in colloquial language, social tagging applications are of particular interest to K-12 schools. When given access to complex, interlinked resources such as the Web, students' emergent language to describe what they are finding evolves faster than most teachers can follow. Social tagging affords students the ability to use their words to describe content and their words to search for content. Social tagging of files and web pages within student 
communities is a direct and intuitive way to label and access relative content, parallel to how students think about resource navigation in their lives outside of school and easier than the top-down, elaborate, nested hierarchies of pre-specified, narrowly defined terms that characterize formal classification frameworks, such as the Dewey Decimal System.

Further, the same direct access to content that benefits students in social tagging networks can assist teachers in their professional development. Without having to browse through huge educational repositories organized by formal classification frameworks, school communities can efficiently share and find worksheets, lesson plans, and other teacher-related materials in affiliative social tagging networks. For all these reason, sociosemantic networking holds considerable promise of value for small learning communities, such as those characterized by consortia of rural schools.

Interviewer: I do hope that the field of education is outgrowing the "This new medium is magic!" syndrome. Can you discuss what the implications of online learning are for teacher preparation programs? Are schools of education keeping up with the ever changing world of online technology? Or are we facing a crisis of teachers under-prepared to use technology effectively in their teaching?

[CD] My recent book about methods for online teacher professional development (http://www .hepg.org/hep/book/6) identifies ten well-established models. Here are four that seem a good fit for teacher education as well as teacher professional development:

- The EdTech Leaders Online (ETLO) program at Education Development Center, Inc. focuses on enabling clients to develop their organization's capacity to provide effective online professional development to $\mathrm{K}-12$ teachers and administrators. ETLO courses are conducted entirely online, with teams from a district participating alongside teams from other districts around the country. During an initial course, participants select one of the 30 ETLO workshops to implement during their practicum, become familiar with its contents, and plan all the details of offering it locally. In this model, the participants who have been trained via this learning experience then implement and facilitate online workshops provided by ETLO while receiving ongoing support both from ETLO staff and from an online forum. This model is a good match for consortia of rural schools seeking to build their internal capacity for delivering online professional development tailored to specific objectives.

- The WIDE World teacher professional development program offers online courses designed to foster teachers' application of research-based strategies in planning curriculum and aiding and assessing students' learning. These strategies include the Teaching for Understanding framework, applications of Gardner's theory of multiple intelligences, and the synthesis of these models in differentiating instruction for diverse learners and integrating new technologies to improve student performance. WIDE World's primary format comprises online readings, asynchronous discussions, and interactive tools; a central component of the WIDE World model is tailored support from an expert online coach for every participant. This model illustrates an online professional development program geared to improving teachers' generic pedagogy and assessment strategies.

- PBS TeacherLine provides content-focused online professional development for $\mathrm{K}-12$ teachers with the goals of improving teacher quality and increasing student achievement. Online courses center on the areas of mathematics, reading, science, curriculum and instruction, and the integration of technology to enhance student learning. The courses provide opportunities for teachers to assess the current capabilities and potential misconceptions of their students, with the objectives of supporting teachers as they make decisions that improve their teaching strategies and prompting teachers to develop activities or instructional units that they will try in their 
classrooms. This model exemplifies an online professional development program geared to improving student outcomes in particular subjects.

- The eMentoring for Student Success project is designed to increase student achievement in science by providing early-career middle- and high school science teachers with science-specific mentoring and professional development through an online learning community. Emphasizing inquiry into science content and into the ways students think and learn about science, this model facilitates discussion and collaboration among novice science teachers, experienced science teachers, and research scientists. Each new teacher receives support from a mentor who has taught the same content at the same grade level in the same state, so that conversations about standards, assessment, and curricula take account of local contexts. This model centers on a mentoring-based strategy responsive to individual teacher's specific needs.

The purpose of identifying these resources is not to recommend specific programs, but rather to sketch the range of online teacher education and professional development strategies now available.

Interviewer: Your book on online professional teacher development is surely well-needed! What is the future of K-12 schools and technology? Are we going to move forward or have we reached a threshold where very modest changes will be made over the next few years?

[CD] This is a pivotal time for reinventing the role of information and communications technologies (ICT) in teaching and learning, because emerging tools, applications, media, and infrastructures are reshaping three aspects of education simultaneously:

- The knowledge and skills society wants from the graduates of education are shifting, due to the evolution of a global, knowledge-based economy and a "flat" world.

- Methods of research, teaching, and learning are expanding, as new interactive media support innovative forms of pedagogy.

- The characteristics of students are changing, as their usage of technology outside of academic settings shapes their learning styles, strengths, and preferences.

Combined, these trends suggest that-beyond implementing at scale the types of educational computers and telecommunications research and experience have proven effective-we should also develop alternative models of education that use emerging technologies to reinvent many aspects of teaching, learning, and schooling. We should use ICT to redesign education, not to make historic models of schooling more efficient, but instead to prepare students for the 21st century-simultaneously transforming teaching in light of our current knowledge about the mind.

Interviewer: How do school leaders reconcile experimentation with instructional technology approaches including "developing alternative models of education" and the demands of education policies that suggest more rigidity in curriculum and assessment?

[CD] At present the dominant model for what the curriculum should contain is the federal No Child Left Behind (NCLB) Act, supported by both major political parties and the general public and based on "testto-standard” strategies. Under NCLB, state content standards are developed by disciplinary experts, professional organizations, and various forms of interest groups; high-stakes tests document whether or not students are learning some subset of that content; and individual students, teachers, schools, and districts are rewarded or punished based solely on test performance. In practice, because states' highstakes psychometric tests are typically based on multiple-choice and short-answer items that have no mechanism for assessing attainment of higher order understandings and performances, 21st century competences embedded in state curriculum standards are buried in a mass of lower-level material and 
generally ignored in day-to-day teaching. The curriculum is crowded with low-level facts and recipe-like procedures (e.g., In what year did Columbus discover America? What are the seven steps of historical inquiry?), as opposed to nuanced understandings and performances (i.e., What confluence of technological, economic, and political forces led to the age of exploration around the end of the 15th century? By what process of interpretation of historical data did you reach this conclusion?).

Even though the concept of standards, assessments, and accountability makes sense at a fundamental level, current policies for improving educational achievement based on this concept have many problems from the perspective of preparing today's children for tomorrow's world (Dede, 2005a). For example, current content standards are based on disciplinary "silos" that do not incorporate metrics of contextual value based on degree and kind. Physics experts indicate what pre-college students need to know if they eventually plan to be physicists, historians determine what pupils must master if they are to become professional historians, and so on. This has led to a huge tangle of content and skills that U.S. educators are mandated to cover in just 12 years-an impossible task! Further, much of what is taught within a subject is only useful to the small subset of students who plan to focus on that particular field in college; state curriculum standards in each discipline are typically neither interrelated nor prioritized to emphasize core understandings and performances all students will need to succeed in the 21st century.

Because of the accountability systems built into this model of educational reform, teachers are using weak but rapid instructional methods, such as lecture and drill-and-practice, to race through the glut of recipes, facts, and test-taking skills they are expected to cover. Despite research indicating that guided inquiry, collaborative learning, mentoring, and apprenticeships are far more effective pedagogical strategies, introducing these into school settings is difficult given the crowded curriculum and the need to prepare students for high stakes tests. Simply delivering required information for students' passive absorption takes every second of instructional time. Teachers have no means by which to prioritize what understandings and performances to emphasize in terms of 21st century citizenship; workplace capabilities for the global, knowledge-based economy; and lifelong learning.

Among all these problems, the biggest single issue is that the first generation of high-stakes tests that our nation is using to determine students' educational outcomes has substantial flaws. These are summative, "drive-by" tests, which provide no diagnostic, just-in-time feedback that could help teachers aid struggling students. In addition, while some assessments emphasize on core ideas and measure at least a few higher-order thinking skills, many state legislatures have allocated such limited resources for test development that the resulting instruments often measure only a random assortment of low-level skills and content, rather than core, higher-order 21st century understandings and performances.

Yet this reform movement still has strong bipartisan support and widespread backing from the public. Under these circumstances, researchers, policymakers, practitioners, and the business sector must collaborate in exerting educational leadership to take on the political challenge of arguing what to deemphasize in the curriculum — and why—in order to make room for students to deeply master core 21st century understandings and performances. This is not a situation in which we must eliminate an equivalent amount of current curriculum for each 21st century understanding added, because better pedagogical methods can lead to faster mastery and improved retention, enabling less re-teaching and more coverage within the same timeframe. However, downgrading the importance of some material in the current curriculum is much harder than adding content and skills because omission involves "unlearning." A major challenge in professional development is helping teachers, policy makers, and local communities unlearn the beliefs, values, assumptions, and cultures underlying schools' standard operating practices, such as forty-five minute class periods that allow insufficient time for all but superficial forms of active learning by students. Intellectual, emotional, and social support is essential for "unlearning" and for 
transformational relearning that can lead to deeper behavioral changes to create next-generation educational practices. Educators, business executives, politicians, and the general public have much to unlearn if 21st century understandings are to assume a central place in schooling.

Interviewer: What advice do you have for education leaders and policy makers in providing resources for instructional technology? For example, have primary and secondary school educators solved many of the infrastructure needs (basic hardware, software, connectivity) of schools and really should be concentrating on the professional development of teachers, administrators and staff. Or are many schools still struggling with maintaining/upgrading basic infrastructure?

[CD] While inequities in access and capability will always exist, the educational infrastructures in all communities_rich and poor-are steadily improving. Moreover, people are acquiring many personal devices (computers, personal digital assistants, smart cell phones, portable gaming platforms) purchased for entertainment and communication, but potentially available for educational purposes if we are smart enough to design for these. A larger problem is the need for sophisticated technical and pedagogical support in school settings. Many schools have good infrastructures, but the security measures the district has imposed are so bizarre and draconian that this investment is unusable. Other schools have solid technical support, but teachers lack an educationally experienced mentor who can model effective ways to use technology in the classroom. At this point, I think the human infrastructure is more in need of crucial investments than the technical infrastructure.

Interviewer: What is the future for Chris Dede? Where will you be, and what will you be doing in the next five to seven years?

[CD] I expect to continue with my scholarship and teaching at Harvard, continuing with the three foci that have characterized my work:

- Using design-based research to study the strengths and limits of emerging information and communication technologies, determining which may be the "golden geese" and which are the "wild geese" in terms of education.

- Developing models of effective leadership for overcoming implementation and scaling up challenges in utilizing innovative educational technologies.

- Articulating policies and perspectives about why and how schooling at every level should transform to prepare students for the 21st century.

This is a fascinating time to be in the field of learning technologies, and I certainly enjoy contributing to the initiatives now underway!

Interviewer: Chris, thank you for your insights! All the Best! 